\title{
Enhanced photoactivity on $\mathrm{Ag} / \mathrm{Ag}_{3} \mathrm{PO}_{4}$ composites by plasmonic effect
}

\author{
Mohammed Ashraf Gondal ${ }^{\text {a, }}{ }^{*}$, Xiaofeng Chang ${ }^{\text {a, b }}$, Wei E.I. Sha ${ }^{\text {c }}$, \\ Zain Hassan Yamani ${ }^{\text {a }}$, Qin Zhou ${ }^{\mathrm{d}}$
}

a. Laser Research Group, Physics Department and Center of Excellence in Nanotechnology, King Fahd University of Petroleum and Minerals, Dhahran 31261, Saudi Arabia;

b. College of Materials Science and Technology, Nanjing University of Aeronautics and Astronautics, Nanjing, 211100, China;

c. Department of Electrical and Electronic Engineering, University of Hong Kong, Pokfulam Road, Hong Kong;

d. State Key Laboratory of Environmental Aquatic Chemistry, Research Center for Eco-environmental Sciences, Chinese Academy of Sciences, Beijing 100085, China.

Corresponding author. Tel.: +966 38602351; fax: +966 38602293.

E-mail address: magondal@kfupm.edu.sa (M.A. Gondal). 
Abstract

The work presented here deals with the photoreduction of metallic silver nanoparticles onto the surface of $\mathrm{Ag}_{3} \mathrm{PO}_{4}$ and resulting photo-catalytic activity enhancement towards degradation of dye molecules, namely Rhodamine B (Rh. B) as a model compound, from aqueous solution under UV or visible light irradiation. Our results clearly indicated that the photoactivity of $\mathrm{Ag}_{3} \mathrm{PO}_{4}$ was significantly enhanced by depositing an optimum amount of silver nanoparticles, even though the adsorption kinetics rate and capacity decreased after the silver nanoparticles agglomerate extensively. The surface plasmon resonance (SPR) excited between the silver nanoparticles and $\mathrm{Rh}$. B interface is a physical origin and responsible for the boosted photoactivity, which strongly depends on the specific wavelength of the incident light. This work provides and suggests, a novel scheme for $\mathrm{Ag} / \mathrm{Ag}_{3} \mathrm{PO}_{4}$ composites having plasmonic effect on the interface with detailed experimental and theoretical study. Keywords: $\mathrm{Ag}_{3} \mathrm{PO}_{4}$, photodegradation, surface plasmon resonance (SPR), momentum, surface plasmon polariton (SPP), silver nanoparticles 
Graphical Abstract

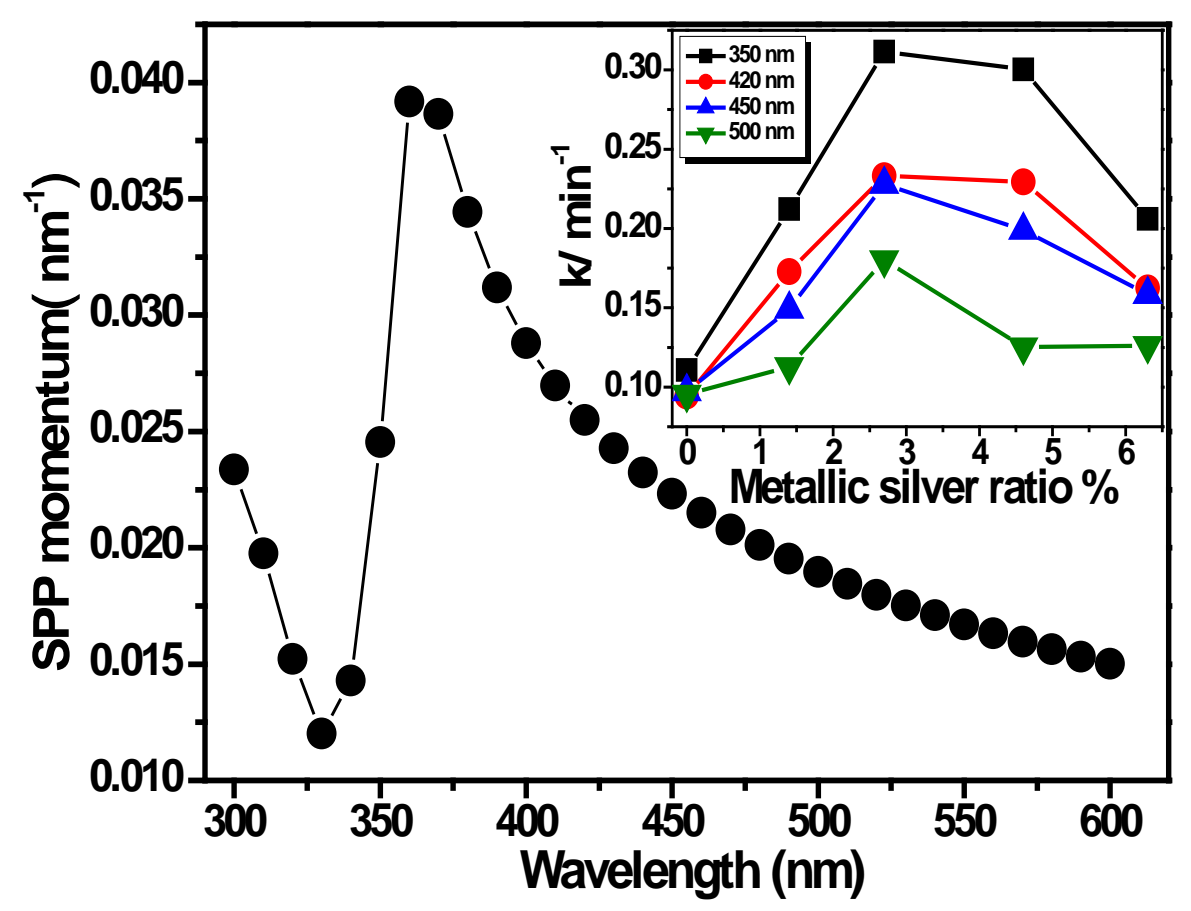

Research highlights

$\mathrm{Ag} / \mathrm{Ag}_{3} \mathrm{PO}_{4}$ composites with different molar ratios have been prepared.

The photoactivity is strongly dependent on the wavelength of the incident light.

The photoactivity is dependent on the molar ratio of $\mathrm{Ag} / \mathrm{Ag}_{3} \mathrm{PO}_{4}$ as well.

Simulation results suggest a good agreement with our experimental observations. 


\section{Introduction}

Heterogeneous photocatalysis technology has become a promising approach to solve energy and environmental problems since 1972 [1]. The concept of "low-carbon \& green life" as well as the pioneer achievements by scholars such as Asahi [2], Zou and Ye [3] are inspiring and great enthusiasm to develop highly efficient photocatalysts to improve the quantum efficiency under visible light (380-780nm) which represents around $42 \%$ of the total light spectrum of the solar radiations $[4,5]$.

In early 2010, silver orthophosphate $\left(\mathrm{Ag}_{3} \mathrm{PO}_{4}\right)$ was reported as an active semiconductor which showed an extremely high photo-catalytic performance with quantum efficiency over $90 \%$ at wavelengths longer than $420 \mathrm{~nm}$ [6]. Soon after, synthesis of single-crystalline $\mathrm{Ag}_{3} \mathrm{PO}_{4}$ sub-micro crystals with selective facets [7], colloidal $\mathrm{Ag}_{3} \mathrm{PO}_{4}$ nanocrystals [8], $\mathrm{Ag}_{3} \mathrm{PO}_{4}$ sub-microcrystals [9, 10], $\mathrm{Ag}_{3} \mathrm{PO}_{4}$ nanowires [11] and $\mathrm{AgX} / \mathrm{Ag}_{3} \mathrm{PO}_{4}(\mathrm{X}=\mathrm{Cl}, \mathrm{Br}, \mathrm{I})$ [12] composites were reported. It has been widely documented and experimentally confirmed that the $\mathrm{Ag}_{3} \mathrm{PO}_{4}$ could be partially reduced to metallic Ag under visible light illumination, which undesirably leads to the catalyst leaching. However, a recent work by Huang et al. demonstrated that a combination of metallic silver with a series of silver salts based photocatalysts, can improve their photocatalytic activity to different extents, depending on the types of negatively charged ions (e.g., $\mathrm{Cl}^{-}, \mathrm{Br}^{-}, \mathrm{I}^{-}, \mathrm{CrO}_{4}{ }^{2-}, \mathrm{PO}_{4}{ }^{3-}, \mathrm{PW}_{12} \mathrm{O}_{40}{ }^{3-}$ and $\mathrm{SiW}_{12} \mathrm{O}_{40}{ }^{4-}$ ) in the corresponding semiconductor crystals [13]. The photocatalytic activity enhancement was attributed to localized surface plasmon resonance (LSPR) induced by metallic silver nanoparticles deposited on the surfaces of the silver salt 
photocatalysts.

Generally, surface plasmon resonance (SPR) for planar surfaces or localized surface plasmon resonance (LSPR) for nanoscaled metal particles can be induced by the excitation of surface plasmons (also known as surface plasmon polaritons, SPP) by using proper wavelength photons. The unique properties of surface plasmon have found a number of promising applications, such as heterogeneous photocatalysis $[14,15]$, sensors [16], photovoltaic cell $[17,18]$.

Although the plasmonic effect of metallic nanoparticles on photocatalysis has been reported recently using wide spectrum of visible light for various photocatalysts, the report on monochromatic responses of these materials in terms of photocatalytic enhancement is very rare. As it is known, the extent of SPR and LSPR are highly dependent on the wavelengths of incident photons, so investigation of monochromatic response of these materials deserves much more attentions than it currently receives. In this investigation, a series of $\mathrm{Ag} / \mathrm{Ag}_{3} \mathrm{PO}_{4}$ composites were prepared by a facile photochemical method and their monochromatic response (i.e., 350, 420, 450, 500nm) was investigated by photodegradation of a model compound (i.e, Rhodamine B (Rh. B)). Rh. B photodegradation in water was found to be strongly dependent on the wavelength of incident light and the amount of surface silver nanoparticles on $\mathrm{Ag}_{3} \mathrm{PO}_{4}$, which is substantiated well by physics simulation results.

\section{Experimental and Calculation method}

2.1 Experimental method

2.1.1 Preparation of $\mathrm{Ag} / \mathrm{Ag}_{3} \mathrm{PO}_{4}$ composites 
All the chemicals used in this study were of analytical grade and used as received without further purification. Absolute ethanol $\left(\mathrm{C}_{2} \mathrm{H}_{5} \mathrm{OH}\right)$, silver nitrate $\left(\mathrm{AgNO}_{3}\right)$, disodium hydrogen phosphate $\left(\mathrm{Na}_{2} \mathrm{HPO}_{4}\right)$ and Rhodamine $\mathrm{B}(\mathrm{Rh} . \mathrm{B})$ were purchased from Sigma Aldrich. Ultrapure Milli-Q water obtained by Millipore was used for the preparation of solutions.

Semiconductor compound of $\mathrm{Ag}_{3} \mathrm{PO}_{4}$ was prepared as per procedure described in the literature [6] by using $\mathrm{AgNO}_{3}$ and $\mathrm{Na}_{2} \mathrm{HPO}_{4}$ as the starting materials. The obtained $\mathrm{Ag}_{3} \mathrm{PO}_{4}$ powders of 2 grams dispersed in water of $200 \mathrm{~mL}$ were then irradiated under full-arc light emitted from Xenon lamp having power of 300 Watts (Beijing Trusttech Co. Ltd., PLS-SXE-300) for different time of 1, 2, 5 and 10 hours. The final products were obtained after separation from water by centrifugation at 10, $000 \mathrm{rpm}$, washing with absolute ethanol/water several times and drying at $60{ }^{\circ} \mathrm{C}$. The as-prepared series composites were named according to the preparation conditions as illustrated by “Ag/ $\mathrm{Ag}_{3} \mathrm{PO}_{4}-\mathrm{x}$ ”, where “ $\mathrm{x}$ ” denotes the irradiation time (hour) for the preparation.

\subsubsection{Characterization}

The crystal structures of the $\mathrm{Ag} / \mathrm{Ag}_{3} \mathrm{PO}_{4}$ composites before and after photochemical reaction were determined by X-ray diffractometer (XRD, Bruker D8 ADVANCE) with $2 \theta$ scope of $10-90^{\circ}$ using $\mathrm{Cu}-\mathrm{K} \alpha$ X-ray source $(\lambda=0.15418 \mathrm{~nm})$. X-ray photoelectron spectroscopy (XPS) study was carried out by multi-technique surface analyzer (Kratos AXIS Ultra DLD). Scanning transmission electron microscope (STEM) images of samples were taken on a transmission electron microscope (Tecnai T12) and field emission gun-scanning electron microscope (Quanta 600 FEG), 
respectively.

\subsubsection{Adsorption and photocatalytic performance}

Batch experiments were performed in order to investigate the effect of combination of silver nanoparticles with $\mathrm{Ag}_{3} \mathrm{PO}_{4}$ on sorption capacity towards probe molecules (Rh. B). Aqueous solution of Rhodamine dye with desired concentration was prepared and required amount of $\mathrm{Ag} / \mathrm{Ag}_{3} \mathrm{PO}_{4}$ composite was added and the resulting suspension was shaken in an orbital shaker (150 rpm) at room temperature. After experiments, the catalyst was separated by centrifugation at $10,000 \mathrm{rpm}$ and the absorbance of Rh.B was determined by UV-vis spectrophotometer (UV-2550, Shimadzu) following the absorption maxima $\left(\lambda_{\max }\right)$ of dye which was found to be at $554 \mathrm{~nm}$.

The adsorption kinetics is one of the most significant tool to describe the adsorption behavior of any compound. In this study, the pseudo- $1^{\text {nd }}$-order adsorption kinetic model was adopted to evaluate and calculate the solute uptake rate and the corresponding thermal dynamical parameters. The pseudo- $1^{\text {st }}$-order adsorption kinetic equation can be written as follows [19],

$$
\mathrm{q}_{\mathrm{t}}=\mathrm{q}_{\mathrm{e}}\left(1-\mathrm{e}^{-\mathrm{k}_{1} \mathrm{t} / 2.303}\right)
$$

where $\mathrm{q}_{\mathrm{t}}\left(\mu \mathrm{mol} \mathrm{g}^{-1}\right)$ is the adsorption capacity at specific contact time, $\mathrm{k}_{1}\left(\mathrm{~min}^{-1}\right)$ is the pseudo- $\mathrm{S}^{\text {st }}$-order kinetic constant and $\mathrm{t}$ is the adsorption time.

Adsorption isotherm is another significant approach to evaluate the adsorption capacity of adsorbents as well as to understand the interactions between adsorbate and adsorbent. To investigate the isothermal behavior of Rh. B adsorption, typical isothermal models i.e. Langmuir and Freundlich, were adopted. 
For Langmuir model, the adsorption can be expressed as follows [20]:

$$
\mathrm{q}_{\mathrm{e}}=\frac{\mathrm{q}_{\mathrm{m}} \mathrm{K}_{\mathrm{L}} \mathrm{C}_{\mathrm{e}}}{1+\mathrm{K}_{\mathrm{L}} \mathrm{C}_{\mathrm{e}}}
$$

where $\mathrm{q}_{\mathrm{e}}$ is the adsorption amount at equilibrium $\left(\mu \mathrm{mol} \mathrm{g}^{-1}\right), \mathrm{C}_{\mathrm{e}}$ is the equilibrium concentration of the aqueous solution $\left(\mu \mathrm{mol} \mathrm{L} \mathrm{L}^{-1}\right), \mathrm{q}_{\mathrm{m}}$ is the maximum adsorption capacity ( $\mu \mathrm{mol} \mathrm{g}{ }^{-1}$ ) and $\mathrm{K}_{\mathrm{L}}$ is the constant related to the free energy of adsorption ( $\mathrm{L}$ $\left.\mathrm{mg}^{-1}\right)$.

The Freundlich model for adsorption of Rh.B can be written as follows [21]:

$$
\mathrm{q}_{\mathrm{e}}=\mathrm{K}_{\mathrm{F}} \mathrm{C}_{\mathrm{e}}^{1 / \mathrm{n}}
$$

where $\mathrm{K}_{\mathrm{F}}$ ( $\mu$ mol ${ }^{1-(1 / n)} \mathrm{L}^{1 / n} \mathrm{~g}^{-1}$ ) and $\mathrm{n}$ are two constants indicating the relative adsorption capacity and the intensity of the adsorption, respectively. The symbols $\mathrm{q}_{\mathrm{e}}$ and $\mathrm{C}_{\mathrm{e}}$ represent the adsorption amount at equilibrium $\left(\mu \mathrm{mol} \mathrm{g}^{-1}\right)$ and equilibrium concentration of the aqueous solution $\left(\mu \mathrm{mol} \mathrm{L} \mathrm{L}^{-1}\right)$, respectively.

A 300 W Xenon lamp (Beijing Trusttech Co. Ltd., PLS-SXE-300) was selected as the light source. Series of band-pass filters (350 nm, 420 nm, 450 nm, 500 nm and 550 $\mathrm{nm}$ ) were used to obtain different wavelengths as incident monochromatic light. After photochemical reactions, the catalyst was removed by centrifugation $(14,000 \mathrm{rpm})$ and the absorbance of the resulting dye solution was determined.

2.2 Calculation method for scattering cross section [22-24]:

The scattering cross section, which can estimate the scattering strength of a metallic nanostructure, is defined by 


$$
\sigma_{s}=\frac{\int_{s} \operatorname{Re}\left[\frac{1}{2} E^{S} \times \operatorname{conj}\left(H^{S}\right)\right] \cdot d S}{\left|S_{i}\right|}
$$

where "conj” denotes the complex conjugation, S is an arbitrary surface enclosing the metallic nanostructure, $S_{i}=\frac{1}{2}\left[E^{i} \times \operatorname{conj}\left(H^{i}\right)\right]$ is the incident energy flux, and $E^{s}$ and $H^{s}$ are the scattered electric and magnetic fields, respectively.

The scattering cross section of a nanosphere can be obtained from Mie series or the generalized reflection coefficient of the spherically layered media

$$
\sigma_{s}=\frac{2 \pi}{K_{2}^{2}} \sum_{m=1}^{\infty}(2 m+1)\left(\left|R_{2,1}^{T M}(m)\right|^{2}+\left|R_{2,1}^{T E}(m)\right|^{2}\right)
$$

where 1 and 2 denote the metallic (silver) and the dielectric (Rhodamine B aqueous solution) background layer, respectively, $\mathrm{m}$ is the order of the modified spherical Bessel (Hankel) functions, and $R_{2,1}^{T M}$ and $\boldsymbol{R}_{2,1}^{T E}$ are the generalized reflection coefficients of the TM and TE spherical waves in the layer 2 reflected by the layer 1 . For small spherical particles, the leading term $(\mathrm{m}=1)$ of $\boldsymbol{R}_{2,1}^{T M}$ determines the value of the scattering cross section, which is given by

$$
R_{i, i-1}^{T M}=\frac{\sqrt{\varepsilon_{i} \mu_{i-1}} \hat{J}_{m}\left(K_{i} r_{i-1}\right) \hat{J}_{m}^{\prime}\left(K_{i-1} r_{i-1}\right)-\sqrt{\varepsilon_{i-1} \mu_{i}} \hat{J}_{m}^{\prime}\left(K_{i} r_{i-1}\right) \hat{J}_{m}\left(K_{i-1} r_{i-1}\right)}{\sqrt{\varepsilon_{i-1} \mu_{i}} \hat{J}_{m}\left(K_{i-1} r_{i-1}\right) \hat{H}_{m}^{(1) !}\left(K_{i} r_{i-1}\right)-\sqrt{\varepsilon_{i} \mu_{i-1}} \hat{H}_{m}^{(1)}\left(K_{i} r_{i-1}\right) \hat{J}_{m}^{\prime}\left(K_{i-1} r_{i-1}\right)}
$$

where $r_{i}, \varepsilon_{i}$ and $K_{i}$ are the radius, permittivity, permeability, and wave number of the $i$ th spherical layer, respectively. The scattering cross section can be normalized to the geometrical cross section of the nanosphere. 
3. Results and discussion
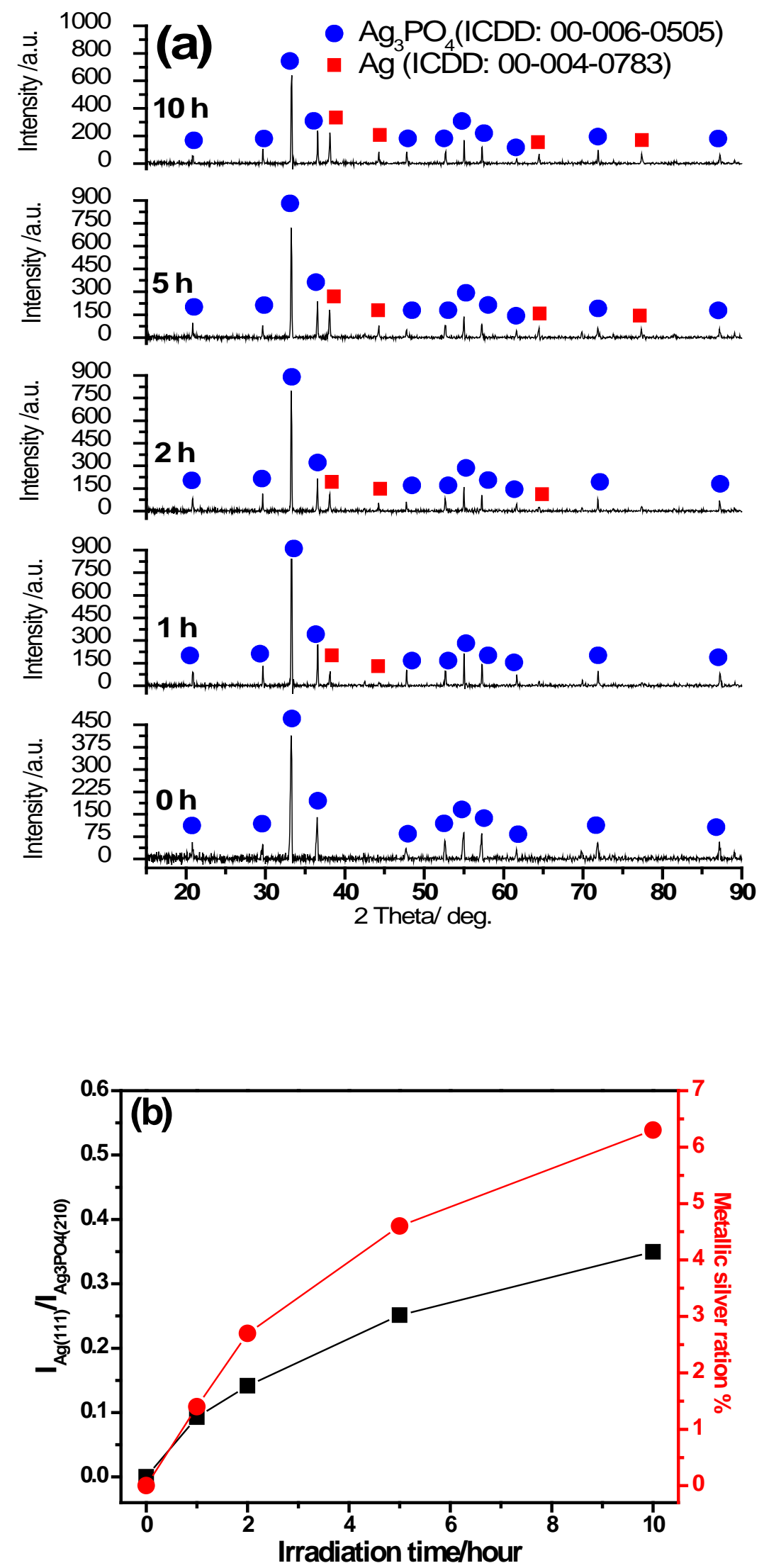


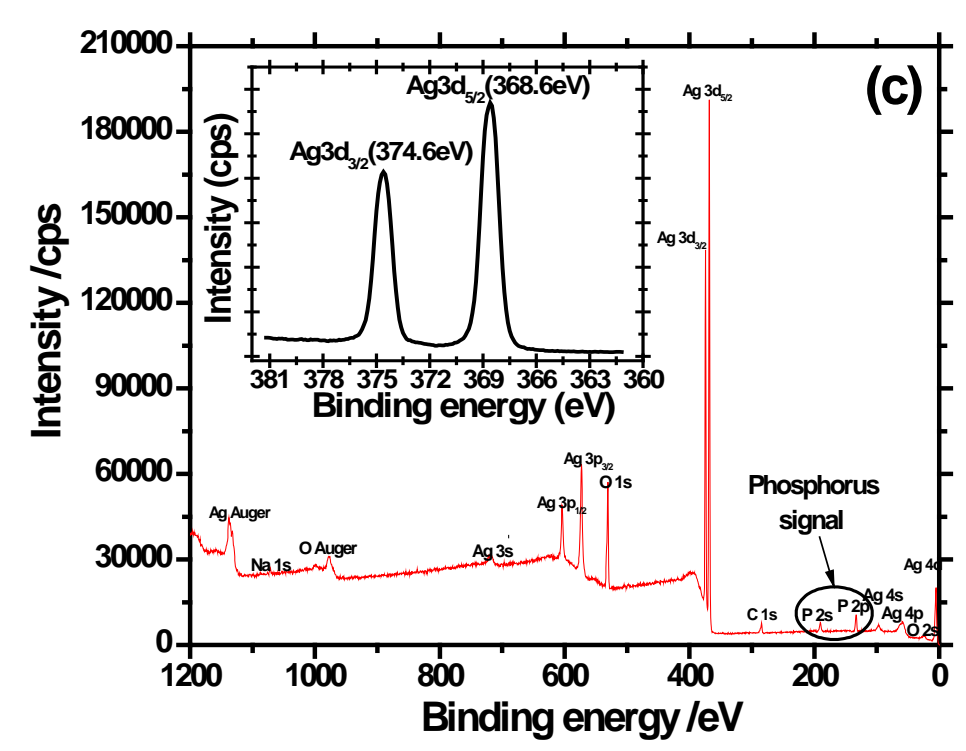

Figure 1. XRD patterns of $\mathrm{Ag} / \mathrm{Ag}_{3} \mathrm{PO}_{4}$ samples prepared under visible light irradiation for 0 h (i.e. pure phase of $\mathrm{Ag}_{3} \mathrm{PO}_{4}$ ), 1, 2, 5 and 10 hours (a); changes of diffraction intensity ratios of $\mathrm{Ag}(111) / \mathrm{Ag}_{3} \mathrm{PO}_{4}$ (210) and metallic silver ratios as a function of photochemical reaction time. (secondary axis has an error: 'ration' is a mistake of 'ratio'.), as well as low resolution XPS of $\mathrm{Ag} / \mathrm{Ag}_{3} \mathrm{PO}_{4}$ prepared by irradiating $\mathrm{Ag}_{3} \mathrm{PO}_{4}$ powder for 2 hours (inset figure depicts the high-resolution XPS)

Figure 1(a) depicts XRD patterns of the $\mathrm{Ag} / \mathrm{Ag}_{3} \mathrm{PO}_{4}$ composites synthesized under different irradiation time. Clearly, after a certain time duration of visible light irradiation, the characteristic XRD patterns of the $\mathrm{Ag}_{3} \mathrm{PO}_{4}$ remained more or less unaffected. However some new peaks, such as at $38.1^{\circ}, 44.2^{\circ}, 64.5^{\circ}$ and $77.4^{\circ}$ emerged, which can be ascribed to the silver crystal indexes of (111), (200), (220) and (311), respectively. This confirms the formation of $\mathrm{Ag}$ on the surfaces of $\mathrm{Ag}_{3} \mathrm{PO}_{4}$. Figure 1(b) depicts the changes of the strongest diffraction intensity ratio 
$\left(\mathrm{I}_{\mathrm{Ag}(111)} / \mathrm{I}_{\mathrm{Ag} 3 \mathrm{PO}(210)}\right)$ with the irradiation time. A non-linear increase of $\mathrm{I}_{\mathrm{Ag}(111)} / \mathrm{I}_{\mathrm{Ag} 3 \mathrm{PO}(210)}$ ratios with irradiation time implies that the phase ratios of $\mathrm{Ag} / \mathrm{Ag}_{3} \mathrm{PO}_{4}$ were gradually headed to a saturation regime with a prolonged irradiation time. A possible explanation might be that the in-situ formed silver nanoparticles deposited on and covered the surface of $\mathrm{Ag}_{3} \mathrm{PO}_{4}$, which in turn inhibits the photochemical reduction of $\mathrm{Ag}_{3} \mathrm{PO}_{4}$ to $\mathrm{Ag}^{0}$ because the surface silver nanoparticles could isolate photo-generated holes from water molecules and could block the visible light absorption of $\mathrm{Ag}_{3} \mathrm{PO}_{4}$ to a certain extent. The amount of metallic silver that was formed was estimated to be around $1.4 \%, 2.7 \%, 4.6 \%$ and $6.3 \%$ (wt $\%$ ) of the samples under the irradiation for 1 , 2, 5 and 10 hours (Figure 1(b).

XPS results indicate that as-prepared samples were composed of silver, oxygen and phosphorus(Figure 1(c)). The existence of phosphorus and oxygen signals in the XPS pattern reveals that metallic silver nanoparticles could not completely cover the surface of $\mathrm{Ag}_{3} \mathrm{PO}_{4}$. The spin-orbit peaks centered at $374.6 \mathrm{eV}$ and $368.6 \mathrm{eV}$ (inset figure), which were corrected with a reference to C 1 s (284.6 eV), correspond to the binding energy of $\mathrm{Ag}_{3} \mathrm{~d}_{3 / 2}$ and $\mathrm{Ag}_{3} \mathrm{~d}_{5 / 2}$ respectively, confirming the formation of metallic silver surface on the surface of $\mathrm{Ag}_{3} \mathrm{PO}_{4}$.

The formed silver nanoparticles can be clearly observed from SEM images of as-prepared samples (see the Supporting Information, Figure S1). Based on the characterization results above, we could assume the average diameters of metallic silver and $\mathrm{Ag}_{3} \mathrm{PO}_{4}$ are $0.05 \mu \mathrm{m}$ and $1 \mu \mathrm{m}$, respectively. Therefore the mass of each $\mathrm{Ag}_{3} \mathrm{PO}_{4}$ particle can be obtained at $3.31 \times 10^{-12} \mathrm{~g}\left(\rho\left(\mathrm{Ag}_{3} \mathrm{PO}_{4}\right)=6.37 \mathrm{~g} \cdot \mathrm{cm}^{-3}\right)$. If a thin 
film of silver (with thickness of $50 \mathrm{~nm}$ ) covers one $\mathrm{Ag}_{3} \mathrm{PO}_{4}$ particle completely (i.e. monolayer coverage), the needed mass of metallic silver is at least $1.82 \times 10^{-12} \mathrm{~g}$ $\left(\rho(A g)=10.5 \mathrm{~g} \cdot \mathrm{cm}^{-3}\right)$, i.e. the coverage ratio of metallic silver should be $\geq 55.0 \mathrm{wt} \%$. Our semi-quantification results suggest that the metallic silver ratios for all the samples are less than $10 \%$ which are far lower than the theoretical value. Therefore it can be deduced that the surface of $\mathrm{Ag}_{3} \mathrm{PO}_{4}$ can not be completely covered by photoreduced metallic silver nanoparticles in this study. These theoretical results are well in agreement with the experimental results of SEM and XPS.

Low-resolution STEM characterization shows that some black points could form after irradiation by electron beam, which clearly shows the low stability of $\mathrm{Ag}_{3} \mathrm{PO}_{4}$ under electron irradiation and the reduction of Ag (bonded) by electron beam irradiation. Unfortunately, we were failed to obtain the STEM images of the as-prepared composite samples due to the instability of silver phosphate under electron beam (see the Supporting Information, Figure S2).

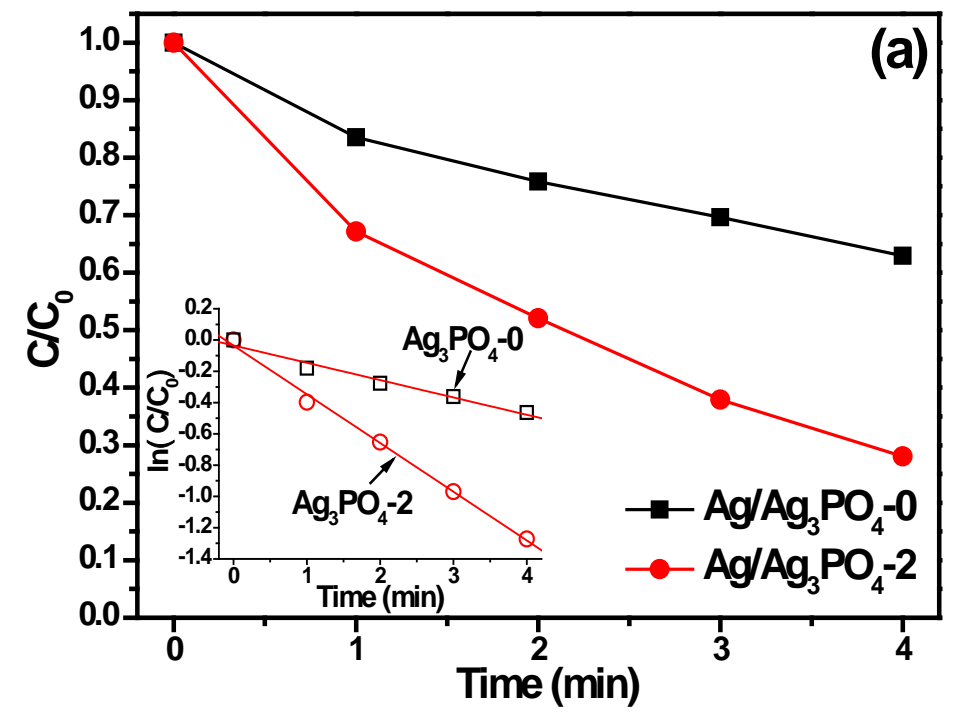




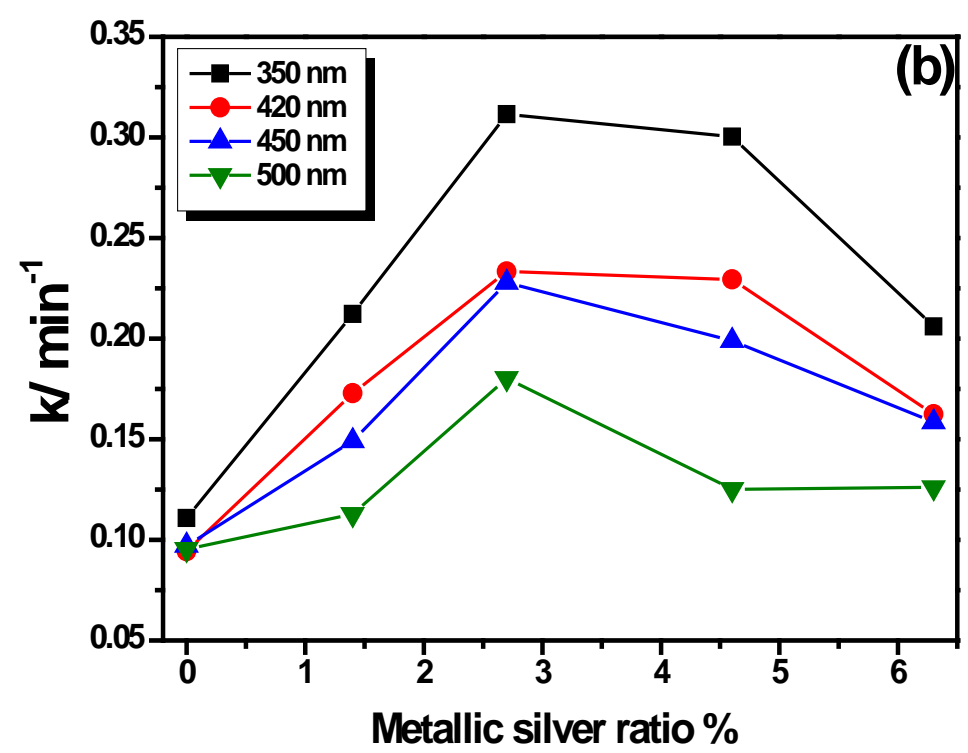

Figure 2. Concentration variation $\left(\mathrm{C} / \mathrm{C}_{0}\right)$ of $\mathrm{Rh}$. B over $\mathrm{Ag} / \mathrm{Ag}_{3} \mathrm{PO}_{4}-0$ and $\mathrm{Ag} / \mathrm{Ag}_{3} \mathrm{PO}_{4}-2$ under monochromatic lights (350 nm) irradiation (a), and effect of irradiation of different monochromatic lights on pseudo- $1^{\text {st }}$-order kinetic constants of metallic silver coverage amount (b) (dosage $=40 \mathrm{mg} / 80 \mathrm{~mL}$ ).

Our results of Rh. B photodegradation under monochromatic irradiation show that a combination of silver and $\mathrm{Ag}_{3} \mathrm{PO}_{4}$ (i.e., $\mathrm{Ag} / \mathrm{Ag}_{3} \mathrm{PO}_{4}$ ) significantly enhanced the photocatalytic activity of $\mathrm{Ag}_{3} \mathrm{PO}_{4}$. As an example, Figure 2 compares Rh. B photo-degradation under $350 \mathrm{~nm}$ on $\mathrm{Ag} / \mathrm{Ag}_{3} \mathrm{PO}_{4}-2$ with pure $\mathrm{Ag}_{3} \mathrm{PO}_{4}$ under same conditions. At 4 minutes, $72 \%$ of Rh. B was degraded on $\mathrm{Ag} / \mathrm{Ag}_{3} \mathrm{PO}_{4}-2\left(\mathrm{Ag} / \mathrm{Ag}_{3} \mathrm{PO}_{4}\right.$ weight ratio being $2.7 \%$ ) compared with $36.8 \%$ on $\mathrm{Ag}_{3} \mathrm{PO}_{4}$, unmistakably showing a clear photo-catalyic activity enhancement in the presence of metallic silver. Furthermore, the results of Rh. B adsorption kinetics and isotherms show that the presence of silver nanoparticles on $\mathrm{Ag}_{3} \mathrm{PO}_{4}$ actually decreased its adsorption capacity 
towards Rh. B (see the Supporting Information, Figure S3, S4, Table S5, S6), ruling out the possibility of an adsorption contribution to the photocatalytic enhancement in the presence of $\mathrm{Ag}^{0}$.

The photodegradation kinetics of Rh. B degradation in this study is well fitted with Langmuir-Hinshelwood model [25]. The model fitted value of $\mathrm{k}$ obtained for Rh. B degradation on $\mathrm{Ag} / \mathrm{Ag}_{3} \mathrm{PO}_{4}-2$ and $\mathrm{Ag}_{3} \mathrm{PO}_{4}$ was $0.32 \mathrm{~min}^{-1}$ and $0.11 \mathrm{~min}^{-1}$ under 350nm irradiation, indicating an almost threefold enhancement in terms of reaction kinetic rate constant.

The Rh. B photodegradation experiments were also conducted with different monochromatic lights (i.e., 420, 450, 500nm) and with different $\mathrm{Ag} / \mathrm{Ag}_{3} \mathrm{PO}_{4}$ weight ratios and corresponding $\mathrm{k}$ was calculated and presented in Figure 2(b), which describes the dependence of $\mathrm{k}$ on monochromatic wavelengths of incident light and metallic silver ratio \%. No Rh. B degradation could be found in the blank experiments without the presence of photo-catalysts. It can be clearly noticed from the figure that $\mathrm{k}$, under identical experimental conditions, increased with an increase in metallic silver ratio $0.1 \%$ to $2.7 \%$ followed by a decrease at higher values, indicating an optimal level of metallic silver coverage on $\mathrm{Ag}_{3} \mathrm{PO}_{4}$ surface for a maximum photocatalytic activity enhancement. Furthermore, the Rh. B degradation on $\mathrm{Ag} / \mathrm{Ag}_{3} \mathrm{PO}_{4}$ shows an unambiguous dependence on incident light wavelengths where $\mathrm{k}$ is decreasing with increasing the incident wavelengths in our case.

In order to quantify photocatalytic activity enhancement by the presence of metallic silver on $\mathrm{Ag}_{3} \mathrm{PO}_{4}$, we propose a term: enhancement factor $\left(\mathrm{FE}_{\lambda \mathrm{r}}\right)$, which is expressed 
as follows:

$$
\mathrm{FE}_{\lambda \mathrm{r}}=\frac{\mathrm{k}_{\lambda \mathrm{r}}}{\mathrm{k}_{\lambda 0}}
$$

where $\lambda$ and $\mathrm{r}$ denote the wavelength of incident light and metallic silver ratio value respectively; $\mathrm{k}_{\lambda 0}$ and $\mathrm{k}_{\lambda \mathrm{r}}$ represent $\mathrm{k}$ for the photodegradation over pure phase $\mathrm{Ag}_{3} \mathrm{PO}_{4}$ and $\mathrm{Ag} / \mathrm{Ag}_{3} \mathrm{PO}_{4}$ with a metallic silver ratio of $\mathrm{r}$ under incident light $(\lambda)$. The values of $\mathrm{FE}_{\lambda \mathrm{r}}$ obtained under our experimental conditions are listed in Table 1, which clearly demonstrate that $\mathrm{FE}_{\lambda \mathrm{r}}$ has interesting and universal features: (1) with all $\mathrm{FE}_{\lambda_{\mathrm{r}}}$ (from 1.2 to 2.8) being greater than unity, it clearly demonstrates the photoactivity enhancement in all cases in the presence of $\mathrm{Ag}^{0}$; (2) an optimal $\mathrm{Ag}^{0}$ level is present at a value where $\mathrm{FE}_{\lambda \mathrm{r}}$ is the highest for the same $\lambda$; (3) $\mathrm{FE}_{\lambda \mathrm{r}}$ is highly $\lambda$ dependent, with $\mathrm{FE}_{350 \mathrm{r}}>\mathrm{FE}_{420 \mathrm{r}}>\mathrm{FE}_{450 \mathrm{r}}>\mathrm{FE}_{500 \mathrm{r}}$. It should also be noted that it is not the intention of this manuscript to generalize that FE decreases with increasing $\lambda$.

Table 1. Enhancement factors $\mathrm{FE}_{\lambda \mathrm{r}}$ of series of $\mathrm{Ag} / \mathrm{Ag}_{3} \mathrm{PO}_{4}$ samples under monochromatic light irradiation using different wavelengths.

\begin{tabular}{ccccc}
\hline & $\mathrm{r}=1.4 \%$ & $\mathrm{r}=2.7 \%$ & $\mathrm{r}=4.6 \%$ & $\mathrm{r}=6.3 \%$ \\
\hline$\lambda=350 \mathrm{~nm}$ & 1.9 & 2.8 & 2.7 & 1.9 \\
$\lambda=420 \mathrm{~nm}$ & 1.8 & 2.5 & 2.4 & 1.7 \\
$\lambda=450 \mathrm{~nm}$ & 1.5 & 2.3 & 2.0 & 1.6 \\
$\lambda=500 \mathrm{~nm}$ & 1.2 & 1.9 & 1.3 & 1.3 \\
\hline
\end{tabular}



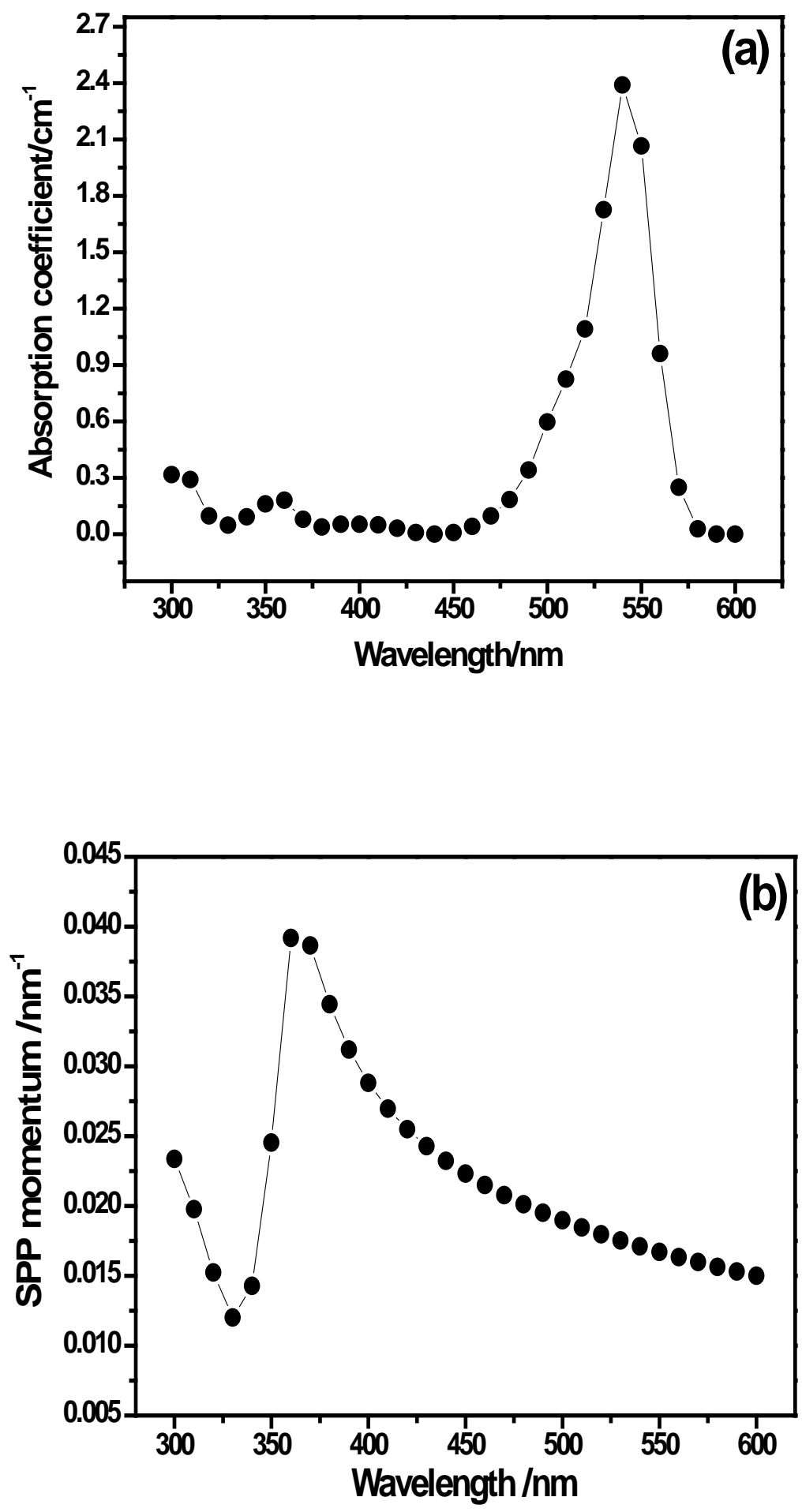


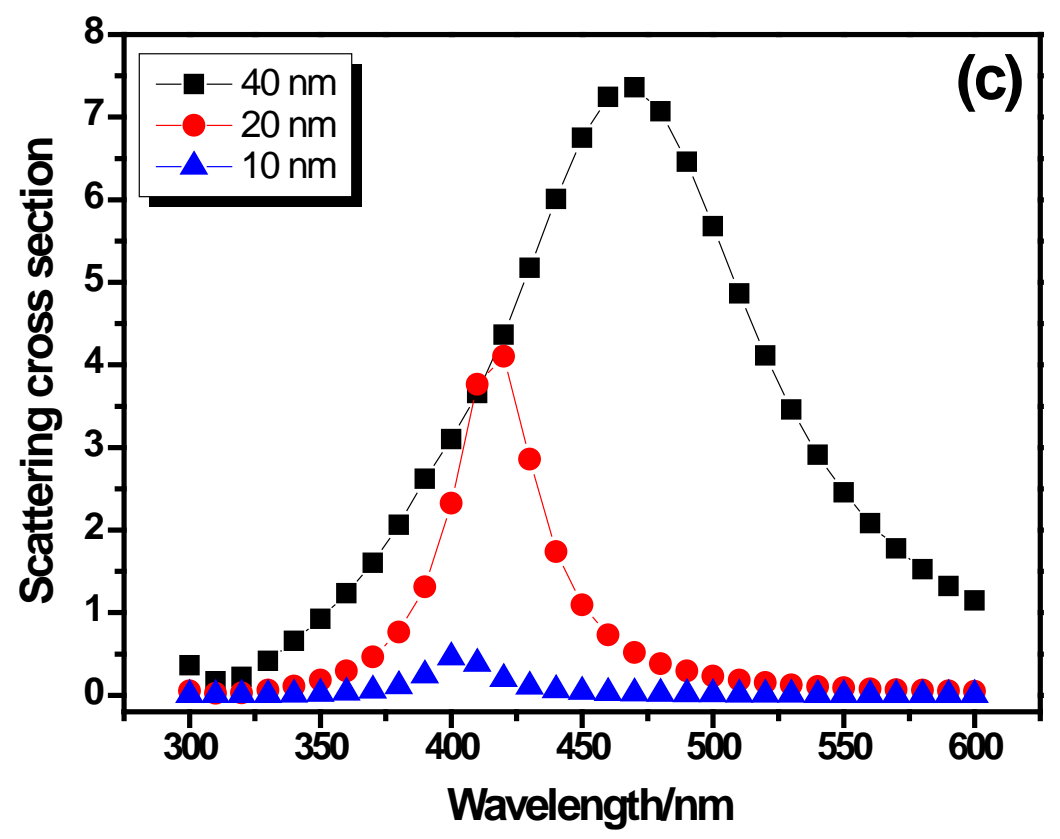

Figure 3: The absorption coefficient of Rh.B aqueous solution with concentration of $10 \mu \mathrm{M}$ (a), scattering cross section of an Ag sphere in Rh. B aqueous solution (b) and momentum of surface plasmon polariton traveling between Ag and Rh. B aqueous solution half spaces (c).

For the first time, our results provide clear evidences that the plasmonic effect of Ag0 on the photoactivity of $\mathrm{Ag}_{3} \mathrm{PO}_{4}$ is $\mathrm{Ag}^{0}$ weight ratio and incident light wavelength dependent. To ascertain the mechanism behind photodegradation performance enhancement, a physics simulation was conducted. When the $\mathrm{Ag}_{3} \mathrm{PO}_{4}$ is illumined by the light, metallic silver nanoparticles are produced on the surface of $\mathrm{Ag}_{3} \mathrm{PO}_{4}$. If the number of silver nanoparticles increase, they will cluster with each other. The radius of the $\mathrm{Ag}_{3} \mathrm{PO}_{4}$ (with micrometer size) is significantly larger than that of the nanosphere and the incident wavelength. Hence, the nanosphere layer can be 
approximated as a planar surface. The real part of the refractive index of contaminated water is approximated as $n=1.33$, the imaginary part of refractive index $k$ can be obtained from that of the model compound. The absorption coefficient of the selected model compound is depicted in Figure 3 (a). Due to the non-uniform photoreduction of silver on the surface of $\mathrm{Ag}_{3} \mathrm{PO}_{4}$, the agglomerated silver particles can form a corrugated metallic layer above $\mathrm{Ag}_{3} \mathrm{PO}_{4}$ surface with a fraction of area. SPRs are electromagnetic excitations propagating at the interface between a dielectric and a metal, evanescently confined in the perpendicular direction. Solving Maxwell's equations under the appropriate boundary conditions yields the dispersion relation of surface plasmon polariton (SPP), that is, the frequency-dependent SPP momentum [26, 27],

$$
\mathrm{k}_{\mathrm{sp}}=\mathrm{k}_{0} \sqrt{\frac{\varepsilon_{\mathrm{d}} \varepsilon_{\mathrm{m}}}{\varepsilon_{\mathrm{d}}+\varepsilon_{\mathrm{m}}}}
$$

where $\mathrm{k}_{0}=\frac{2 \pi}{\lambda}$ is the wave number of free space and $\lambda$ is the wavelength of incident light. The frequency-dependent permittivity of the metal $\varepsilon_{\mathrm{m}}$ and the dielectric material $\varepsilon_{\mathrm{d}}$, must have opposite signs if SPPs are to be possible at such an interface. The complex permittivity of silver can be expressed by the Brendel-Bormann model [28] and that of Rh. B is taken from [29] $\left(\varepsilon_{\mathrm{Ag}}<0\right.$ and $\left.\varepsilon_{\text {Rh.B(aq.) }}>0\right)$.

Therefore SPPs can support at the interface between silver and Rh. B with the momentum as shown in Figure 3 (b), the peak of the SPP momentum indicates a surface plasmon resonance having strong near-field intensity, and the highest SPP momentum of silver nanoparticles which can be reached under incident photons with 
wavelength of $~ 359 \mathrm{~nm}$, which is well coincident with the experimental results and calculated enhancement factor $\left(\mathrm{FE}_{\lambda \mathrm{r}}\right)$. The permittivity of silver is larger than zero and no SPP exists when the incident wavelength becomes smaller than $330 \mathrm{~nm}$. The photoactivity of $\mathrm{Ag} / \mathrm{Ag}_{3} \mathrm{PO}_{4}$ composite is significantly enhanced at the specific wavelength of surface plasmon resonance.

It is worth mentioning that Mie series is employed to compute the scattering cross section of a single silver nanoparticle (assuming the silver particle size of $10 \mathrm{~nm}, 20$ $\mathrm{nm}$ and $40 \mathrm{~nm}$ ) in Rh. B background (as depicted in Figure 3(c)) and the associated LSPR could not have a good spectral agreement with the enhancement peak of photoactivity. However, the agglomeration of silver nanoparticles can not be avoided and the assumption of corrugated thin metallic layer as well as supported surface plasmon resonance is reasonable. Extensive agglomeration of silver nanoparticles will partially cover the $\mathrm{Ag}_{3} \mathrm{PO}_{4}$ surface so that the reaction of $\mathrm{Ag}_{3} \mathrm{PO}_{4}$ with $\mathrm{Rh}$. $\mathrm{B}$ will be gradually inhibited. This is the reason why the adsorption kinetics rate and capacity decreased after the silver particles agglomerate extensively.

\section{Conclusions}

In summary, this paper reports the photodegradation enhancement on $\mathrm{Ag} / \mathrm{Ag}_{3} \mathrm{PO}_{4}$ composites by plasmonic effect. It was found that both factors such as combined metallic silver amount and the wavelength of incident photons could dramatically influence the photoactivity improvement. The highest photoactivity was obtained under an optimum coverage amount of silver nanoparticles (2.7\%) and incident lights having a wavelength of $350 \mathrm{~nm}$. Simulation results suggest that SPR have a good 
spectral agreement with the enhancement peak of photoactivity rather than LSPR.

\section{Acknowledgements}

The support by King Fahd University of Petroleum and Minerals under approved Laser Research Group projects \# Rg1011-1 \& Rg1011-2 is gratefully acknowledged. This study is partially supported by National Natural Science Foundation of China (No. 41103076), Special Foundation of President of the Chinese Academy of Science (No. 312B11YBLWYZJ2011001) and Youth Innovation Promotion Association, CAS.

\section{Appendix A. Supplementary data}

Supplementary data associated with this article can be found, in the online version, at doi:******.

\section{References}

[1] A. Fujishima, K. Honda, Nature 238 (1972) 37-38.

[2] R. Asahi, T. Morikawa, T. Ohwaki, K. Aoki, Y. Taga, Science 293 (2001) 269-271.

[3] Z. Zou, J. Ye, K. Sayama, H. Arakawa, Nature 414 (2001) 625-627.

[4] A. Kudo, Y. Miseki, Chem. Soc. Rev. 38 (2009) 253-278.

[5] C. Chen, W. Ma, J. Zhao, Chem. Soc. Rev. 39 (2010) 4206-4219.

[6] Z. Yi, J. Ye, N. Kikugawa, T. Kako, S. Ouyang, S. Hilary, H. Yang, J. Cao, W. Luo, Z. Li, Y. Liu, R. Withers, Nat. Mater. 9 (2010) 559-564.

[7] Y. Bi, S. Ouyang, N. Umezawa, J. Cao, J. Ye, J. Am. Chem. Soc. 133 (2011) 6490-6492.

[8] C. Dinh, T. Nguyen, F. Kleitz, T. Do, Chem. Commun. 47 (2011) 7797-7799. 
[9] Y.P. Bi , H.Y. Hu , S.X. Ouyang, Z.B. Jiao , G.X. Lu, J.H. Ye, J. Mater. Chem. 22 (2012) 14847-14850.

[10] Y.P. Bi , H.Y. Hu , S.X. Ouyang , Z.B. Jiao , G.X. Lu, J.Y. Cao, J.H. Ye, Chem. Commun. 48 (2012) 3748-3750.

[11] R. Que, Front. Optoelectron. China 4 (2011) 176-180.

[12] Y. Bi, S. Ouyang, J. Cao, J. Ye, Phys. Chem. Chem. Phys. 13 (2011) 10071-10075.

[13] H. Huang, X. Li, Z. Kang, Y. L, H. Li, X. He, S. Lian, J. Liu, S. Lee, Dalton Trans. 39 (2010) 10593-10597.

[14] P. Wang, B. Huang, X. Qin, X. Zhang, Y. Dai, J. Wei, M. Whangbo, Angew. Chem. Int. Ed. 47 (2008) 7931 -7933.

[15] H. Xu, H. Li, J. Xia, S. Yin, Z. Luo, L. Liu, L. Xu, ACS Appl. Mater. Interfaces 3 (2011) 22-29.

[16] A. Baba, P. Taranekar, R. Ramakrishna, W. Knoll, C. Rigoberto, ACS Appl. Mater. Interfaces 2 (2010) 2347-2354.

[17] S. Gao, K. Ueno, H. Misawa, Acc. Chem. Res. 44 (2011) 251-260.

[18] W. Sha, W. Choy, W. Chew, Opt Express 18 (2010) 5993-6007.

[19] Q. Yu, R. Zhang, S. Deng, J. Huang, G. Yu, Water Res. 43 (2009) 1150-1158.

[20] I. Langmuir, J. Am. Chem. Soc. 38 (1916) 2221-2295.

[21] H. Freundlich, Z. Phys. Chem. 57 (1906) 385-470.

[22] C.F. Bohren, D.R. Huffman, Absorption and Scattering of Light by Small Particles (Wiley-Interscience, 1998). 
[23] W.C. Chew, Waves and Fields in Inhomogenous Media (Wiley-IEEE Press, 1999).

[24] L. Tsang, J.A. Kong, K.H. Ding, Scattering of Electromagnetic Waves: Theories and Applications (Wiley, 2000).

[25] K. Kumar, K. Porkodi, F. Rocha, Catal. Commun. 9 (2008) 82-84.

[26] W. Barnes, A. Dereux, T. Ebbesen, Nature 424 (2003) 824-830.

[27] S.A. Maier, Plasmonics: Fundamentals and Applications (Springer, 2007).

[28] A. Rakic, A. Rakic, B. Djurisic, M. Majewski, Appl. Optics 37 (1998) 5271-5283.

[29] B. Rossi, H. Byrne, W. Blau, Appl. Phys. Lett. 58 (1991) 1712-1714. 


\section{Supporting information:}

Enhanced photoactivity on $\mathrm{Ag} / \mathrm{Ag}_{3} \mathrm{PO}_{4}$ composites by plasmonic effect

$$
\begin{gathered}
\text { Mohammed Ashraf Gondal }{ }^{\text {a, }} \text {, Xiaofeng Chang }{ }^{\text {a, b }} \text {, Wei Sha }{ }^{c} \text {, } \\
\text { Zain Hassan Yamani }{ }^{\text {a }} \text {, Qin Zhou }{ }^{\text {d }}
\end{gathered}
$$

a. Laser Research Group, Physics Department and Center of Excellence in Nanotechnology, King Fahd University of Petroleum and Minerals, Dhahran 31261, Saudi Arabia;

b. College of Materials Science and Technology, Nanjing University of Aeronautics and Astronautics, Nanjing, 211100, China;

c. Department of Electrical and Electronic Engineering, University of Hong Kong, Pokfulam Road, Hong Kong;

d. State Key Laboratory of Environmental Aquatic Chemistry, Research Center for Eco-environmental Sciences, Chinese Academy of Sciences, Beijing 100085, China.

Corresponding author. Tel.: +966 38602351; fax: +966 38602293.

E-mail address: magondal@kfupm.edu.sa (M.A. Gondal). 

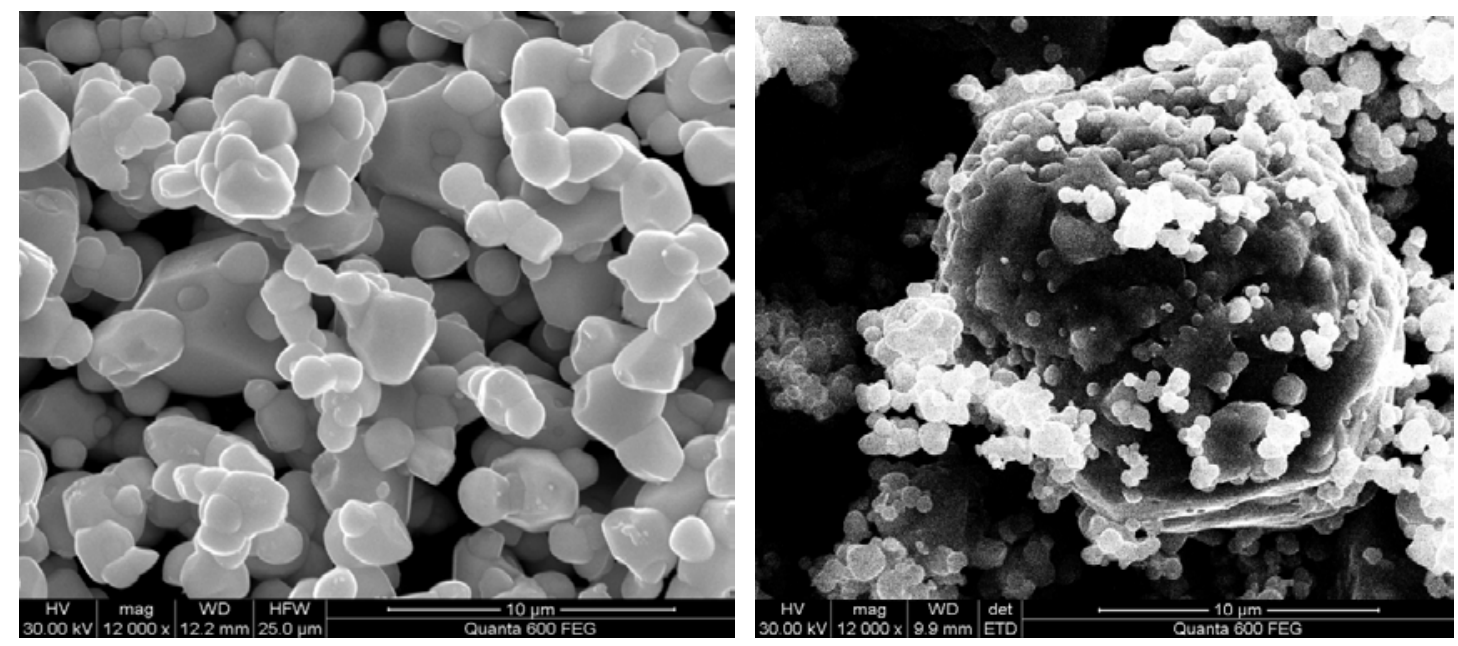

Supporting information Figure S1: SEM image of as-prepared $\mathrm{Ag}_{3} \mathrm{PO}_{4}$ and $\mathrm{Ag} / \mathrm{Ag}_{3} \mathrm{PO}_{4}-2$
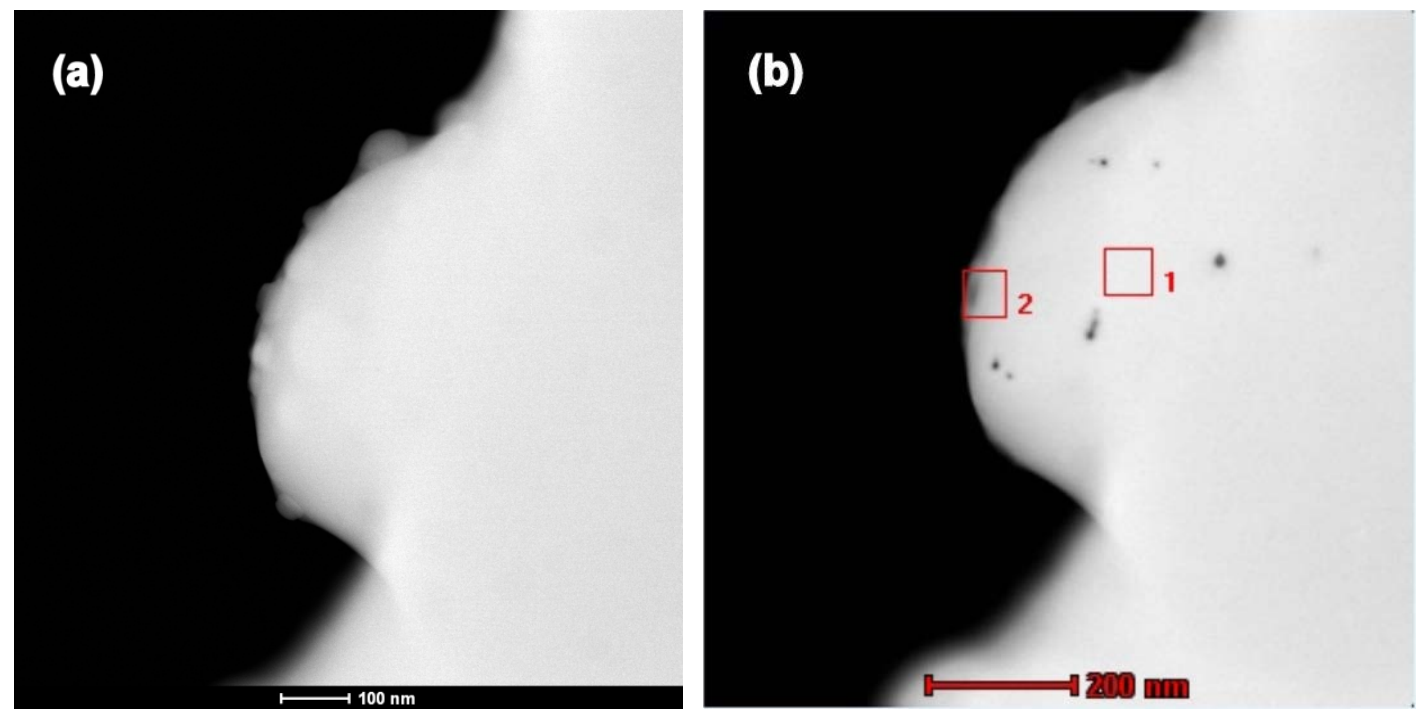

Supporting information Figure S2: Low-resolution STEM images of the $\mathrm{Ag}_{3} \mathrm{PO}_{4}$ sample (a) at the initial point of irradiation and (b) after 1 min of irradiation. 


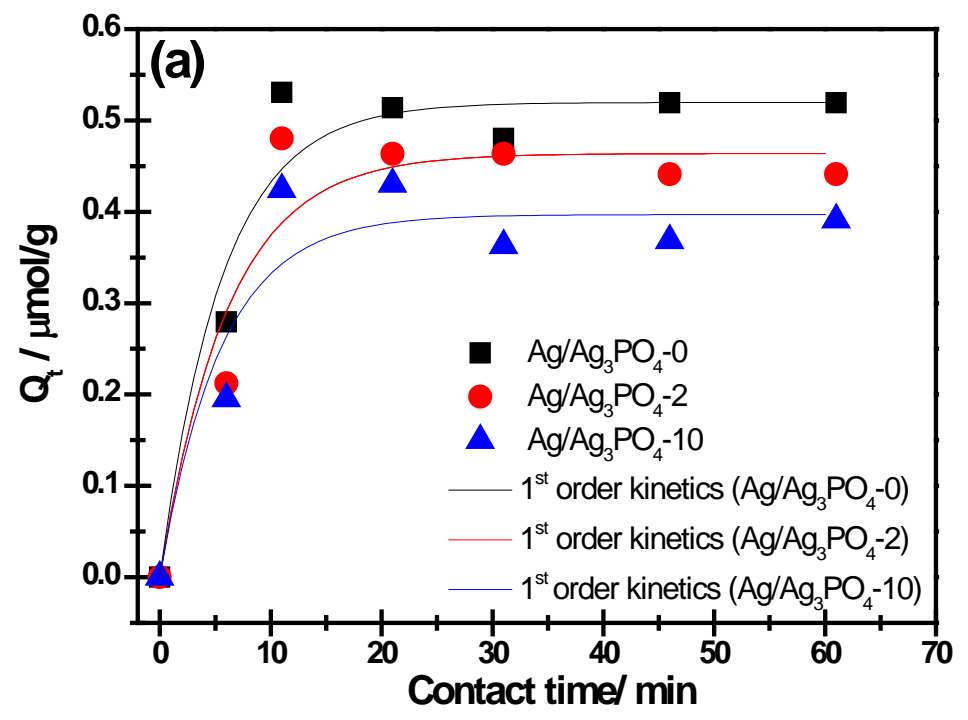

Supporting information Figure S3: Variations of adsorption capacity towards Rh.B as a function of contact time over series $\mathrm{Ag} / \mathrm{Ag}_{3} \mathrm{PO}_{4}$ samples and their $1^{\text {st }}$ order kinetic fitting curves (R.T., $\mathrm{C}_{0}=10.4 \mu \mathrm{M}$, dosage $=0.1 \mathrm{~g} / 40 \mathrm{~mL}$ ).

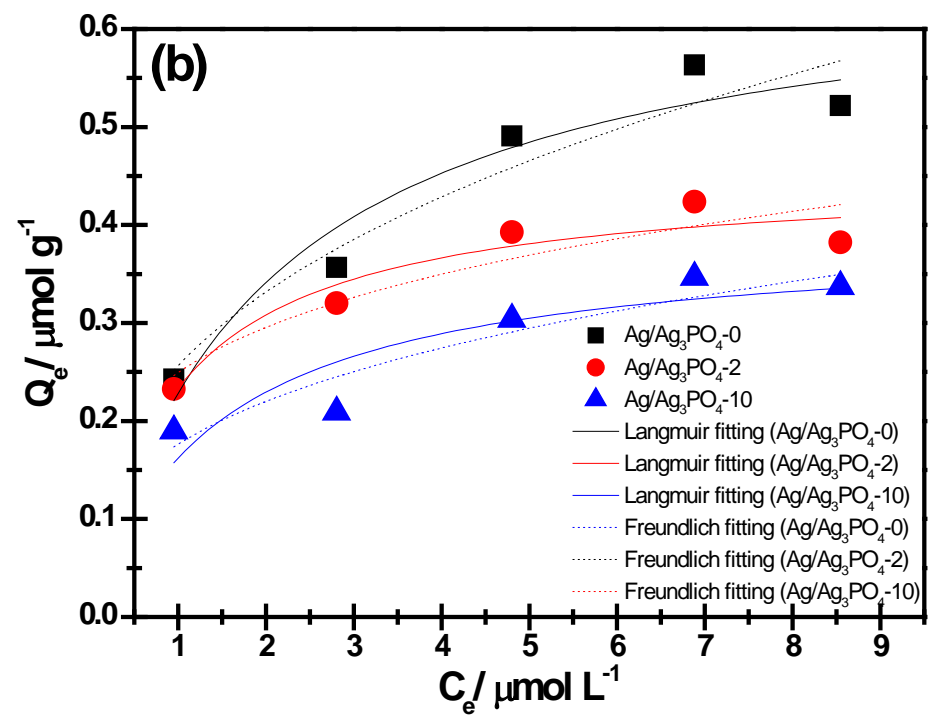

Supporting information Figure S4: Adsorption isotherm scatters of RhB over as-prepared $\mathrm{Ag} / \mathrm{Ag}_{3} \mathrm{PO}_{4}$ samples and their non-linear-fittings through Langmuir and Freundlich models (R.T., dosage $=0.1 \mathrm{~g} / 37 \mathrm{~mL}$ ). 
Supporting information Table S5: Kinetic parameters of the pseudo-first-order for adsorption onto the $\mathrm{Ag} / \mathrm{Ag}_{3} \mathrm{PO}_{4}-0$ and $\mathrm{Ag} / \mathrm{Ag}_{3} \mathrm{PO}_{4}-2$ and $\mathrm{Ag} / \mathrm{Ag}_{3} \mathrm{PO}_{4}-10$ adsorbents.

\begin{tabular}{cccc}
\hline \multirow{3}{*}{ Adsorbents } & \multicolumn{3}{c}{ pseudo-first-order } \\
\cline { 2 - 4 } & $\mathrm{k}_{1}\left(\mathrm{~min}^{-1}\right)$ & $\mathrm{q}_{\mathrm{e}}(\mu \mathrm{mol} / \mathrm{g})$ & $\mathrm{r}^{2}$ \\
\hline $\mathrm{Ag} / \mathrm{Ag}_{3} \mathrm{PO}_{4}-0$ & 0.47528 & 0.51881 & 0.9564 \\
$\mathrm{Ag} / \mathrm{Ag}_{3} \mathrm{PO}_{4}-2$ & 0.37899 & 0.46371 & 0.92037 \\
$\mathrm{Ag} / \mathrm{Ag}_{3} \mathrm{PO}_{4}-10$ & 0.37319 & 0.39689 & 0.89066 \\
\hline
\end{tabular}

Supporting information Table S6: Fitting parameters of the Langmuir and Freundlich equations for adsorption onto the $\mathrm{Ag} / \mathrm{Ag}_{3} \mathrm{PO}_{4}-0$ and $\mathrm{Ag} / \mathrm{Ag}_{3} \mathrm{PO}_{4}-2$ and $\mathrm{Ag} / \mathrm{Ag}_{3} \mathrm{PO}_{4}-10$ adsorbents.

\begin{tabular}{|c|c|c|c|c|c|c|}
\hline \multirow[b]{2}{*}{ Adsorbents } & \multicolumn{3}{|c|}{ Langmuir model } & \multicolumn{3}{|c|}{ Freundlich model } \\
\hline & $\mathrm{q}_{\mathrm{m}}(\mu \mathrm{mol} / \mathrm{g})$ & $\mathrm{K}_{\mathrm{L}}(\mathrm{L} / \mu \mathrm{mol})$ & $r^{2}$ & $\begin{array}{c}\mathrm{K}_{\mathrm{F}} \\
\left(\mu \mathrm{mol}^{1-1 / \mathrm{n}} \mathrm{L}^{1 / \mathrm{n}} \mathrm{g}^{-1}\right)\end{array}$ & $\mathrm{n}$ & $r^{2}$ \\
\hline $\mathrm{Ag} / \mathrm{Ag}_{3} \mathrm{PO}_{4}-0$ & 0.67274 & 0.51464 & 0.93613 & 0.25652 & 2.70204 & 0.92695 \\
\hline $\mathrm{Ag} / \mathrm{Ag}_{3} \mathrm{PO}_{4}-2$ & 0.45422 & 1.0096 & 0.91025 & 0.24733 & 4.07527 & 0.85266 \\
\hline $\mathrm{Ag} / \mathrm{Ag}_{3} \mathrm{PO}_{4}-10$ & 0.41142 & 0.55229 & 0.79923 & 0.16631 & 2.84597 & 0.86552 \\
\hline
\end{tabular}



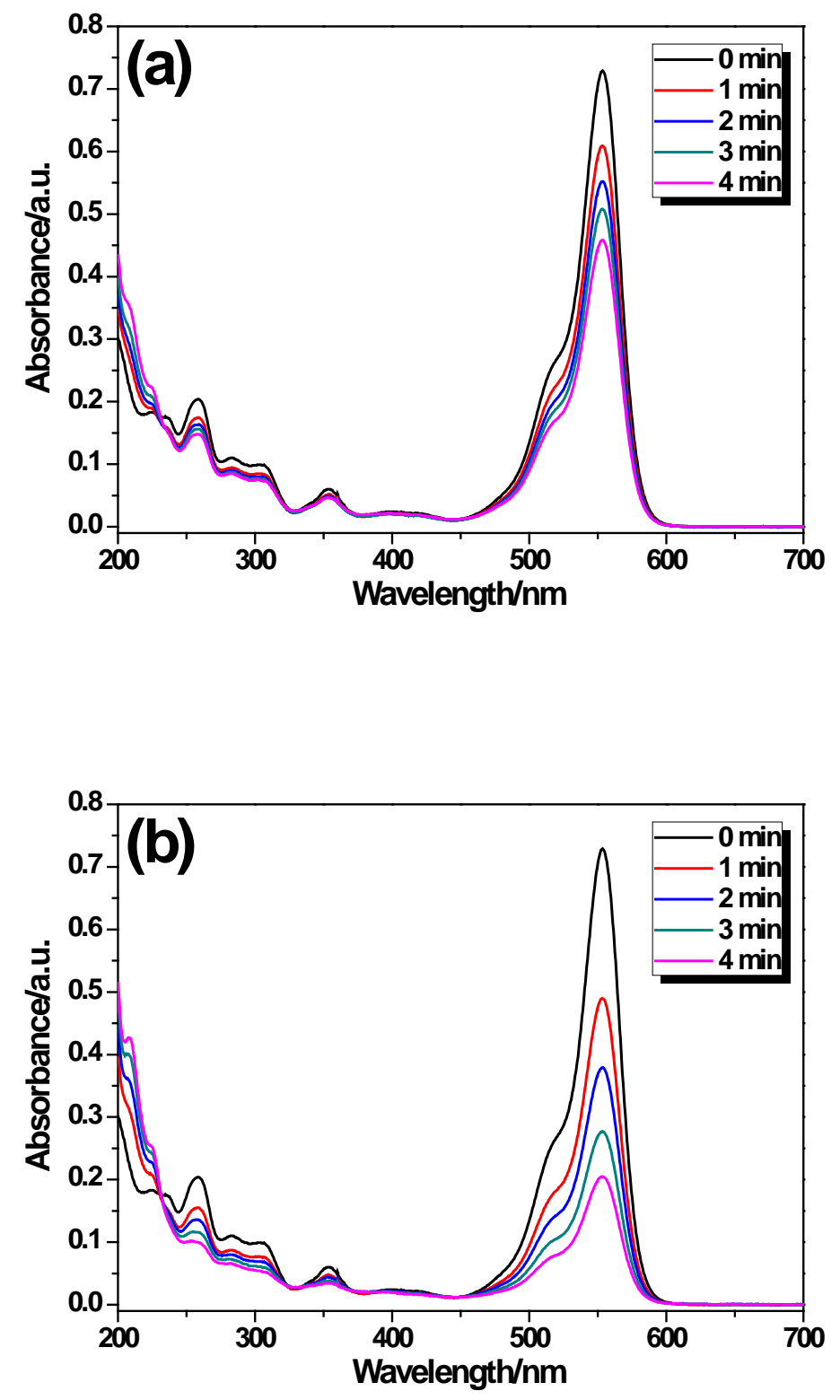

Supporting information Figure S7: UV-vis spectral variations of RhB aqueous solution during the process of visible light-induced degradation over $\mathrm{Ag} / \mathrm{Ag}_{3} \mathrm{PO}_{4}-0$ (a) and $\mathrm{Ag} / \mathrm{Ag}_{3} \mathrm{PO}_{4}-5$ (b), the corresponding kinetic curves of which is depicted in the Figure 2a). 